\title{
COMO ESCOLHER UM EXEMPLO? DE QUALQUER UM PARA QUALQUER UM
}

\author{
Ronaldo Manzi $i^{1}$
}

\begin{abstract}
Resumo: Como escolher um exemplo? O que se passa como um simples dado pode ser o mais complexo: o critério de escolha. Alguns casos servem de exemplo e outros não. Por quê? $\mathrm{O}$ objetivo deste texto é tentar dar algum critério para esse tipo de escolha. O caminho escolhido para tal foi tomar um caso da psicopatologia freudiana: o caso Dora. Por que esse caso é considerado o exemplo de histeria? Para responder a essa questáo, recorre-se ao pensamento de Agamben, principalmente quando se diferencia o exemplo da exceção; além de outros pensadores contemporâneos, recorre-se também a Foucault, quando este nos mostra o que seria o pensamento do exterior. $\mathrm{O}$ texto busca determinar por que o exemplo recai no caso de singularidade - algo que nem é particular e nem universal. Há um paradigma em dar um exemplo: nem todos valem. Por quê?
\end{abstract}

Palavras-chave: Exemplo. Particularidade. Universal. Singular. Modelo.

Como escolher um exemplo? Por que um caso qualquer pode servir de modelo para outros? Poder-se-ia tomar qualquer caso como modelo de explicação de algo? Ora, o que é comum e próprio em cada situação? Como posso generalizar um exemplo? Como fazer essa escolha?

Aparentemente, parece fácil escolher um exemplo. Basta que um caso qualquer nos aponte algo que possa ser generalizado para outros casos. Mas nem sempre um caso "qualquer" consegue abarcar toda a complexidade de "modelo", a fim de que seja o ponto de referência para pensar uma generalida-

${ }^{1}$ Professor do Programa de Pós-Graduação em Educação da Faculdade de Inhumas (FACMAIS), Inhumas, GO - Brasil. (D) https://orcid.org/0000-0001-7980-3997 E-mail: manzifilho@hotmail.com

Psicanalista, Doutor em Filosofia pela Universidade de São Paulo (USP) e pela Radboud University Nijmegen (RUN) (cotutela). Pós-Doutor em Filosofia (USP); Pós-Doutor em Psicologia (USP).

http://dx.doi.org/10.1590/0101-3173.2019.v42n4.10.p187

This is an open-access article distributed under the terms of the Creative Commons Attribution License. 
de. Podemos ter um caso no qual algo aparece e outro caso em que esse "algo" não seja tão relevante, de sorte que esses dois "caiam" num mesmo conjunto.

Na psicanálise, por exemplo, a descrição de um caso serve de modelo para outros. Que se veja o famoso caso Dora de Sigmund Freud. Tem-se já aqui uma nova questão: por que eu mesmo usei Freud como exemplo para pensar o que é exemplo? Esse será o horizonte do texto. Voltemos primeiramente a Freud.

$\mathrm{O}$ que quer que se diga sobre a histeria, de algum modo, deve estar contido no caso Dora. Não só na obra freudiana. Jacques Lacan, por exemplo, ao expor o que é a histeria, recorre ao caso Dora como referência ao conjunto histeria. Mesmo que sua teoria não siga os mesmos passos que a de Freud, o caso é retomado como modelo que vale para se pensar a histeria de uma maneira geral. Afinal, por que esse exemplo serve de modelo para o que se denomina histeria, na psicanálise?

A questão aqui fica mais clara: há casos de histeria nos quais um ponto é mais relevante do que outro e que, se fossem tomados como modelo para outros casos, não conseguiriam abarcar a complexidade do conjunto histeria. O caso Dora, por outro lado, sua singularidade, parece abarcar tudo o que é pertencente ao conjunto histeria.

Poderíamos pensar de forma estrutural: Dora é histérica, porque tem uma estrutura (psíquica) histérica - essa estrutura independe de sua estória, da descrição do caso. Assim, seria contingente o que se deu na análise com Freud, porque o que importaria seria sua estrutura histérica. Mas isso não cairia em qualquer caso? Se se for histérico, não está em jogo uma estrutura histérica? Por que a "estrutura histérica" de Dora seria um modelo? Ou seja, recorrer à questão de estrutura não parece adiantar muito.

Freud descreveu poucos casos, em sua obra. É verdade que encontramos várias passagens, em sua extensa bibliografia. Encontramos também casos pontuais, como da jovem homossexual etc. Todavia, os casos mais extensos e detalhados não passam de cinco. São eles: o caso Dora, já mencionado, o homem dos lobos, o homem dos atos, o pequeno Hans e o caso Schreber. Ou seja, um caso de histeria, dois de neurose obsessiva, um de fobia e outro de psicose. O mais curioso é que se trata de casos que, apesar de se tornarem marcos na psicanálise para se pensar esses diagnósticos, não são todos eles casos de pacientes de Freud e alguns deles nem são casos resolvidos. Ou seja, Freud escolhe como modelo para se pensar a histeria um caso em que ele francamen- 
te diz ter "errado", porque não tinha percebido ainda com clareza o papel da transferência; escolhe também como modelos casos de neurose obsessiva que não foram realmente resolvidos; um caso de fobia que não foi ele que tratou, mas cujo tratamento acompanhou (do psicanalista/pai de Hans); e um caso no qual ele toma como referência um livro em que Schreber descreve, sob seu ponto de vista, seu "destino" e seus delírios.

Por que casos aparentemente tão bizarros são tomados como exemplos? Não é estranho que se escolha um caso não resolvido, por exemplo, como modelo para a histeria? Ainda mais estranho é imaginarmos que Freud, nessa época, está tentando estabelecer a psicanálise como ciência. E ele usa um exemplo de um caso não resolvido como referência para identificar cientificamente o que é histeria. Assim, podemos perguntar: por que esse caso descreve melhor do que outro a histeria? Por que Freud não escolheu simplesmente um caso resolvido e sem "mistério"? Ou será que se escolhe um caso ao acaso? Por que Dora? Ela é uma qualquer? Um caso qualquer, entre outros? Ou há algo de singular em seu caso que o eleva a uma singularidade? Mas existiriam casos não singulares? Toda estória não é singular?

Poucos pensadores se deram o trabalho de tentar explicar por que escolheram um exemplo dentre outros. Poucos disseram realmente o que significa escolher um exemplo ou o que é um exemplo. Por exemplo, encontramos na obra de Lacan escassos exemplos de casos, limitando-se quase ao caso Aimée, desenvolvido em seu doutorado [Da psicose paranoica em suas relaçóes com a personalidade (1932)] e algumas passagens muito breves de casos seus, durante os seus vinte sete anos de seminários (1953-1980). Seria por acaso? Por que ele prefere recorrer aos exemplos de Freud, de maneira a explicar a sua teoria? Um modo de reafirmar que é preciso retomar Freud? Ressignificá-lo, a partir de seus próprios exemplos? Por que não trouxe exemplos da sua própria clínica que fossem mais esclarecedores de sua teoria? No Seminário III, por exemplo, se ele pretende dar uma ênfase na incapacidade do psicótico de se colocar em dúvida, por que recorrer ao caso Schreber? Ele náo teria em sua clínica outro modelo de psicose que destacasse essa estrutura de fixação de forma mais clara? Por que não se utilizar de outro exemplo? Por que os exemplos de Freud se tornam $o$ modelo da clínica psicanalítica?

Heidegger defendeu, em 1927 (Ser e tempo), que todo homem está aberto ao mundo enquanto um ser de possibilidades. Essa concepção do ser do ente do homem o torna absolutamente responsável pelas possibilidades humanas, sejam elas quais forem. Logo, mesmo que um sujeito não seja histérico, 
usando meu exemplo acima, ele carregaria a possibilidade de ser histérico pelo simples fato de ser um ser de possibilidades.

Tradicionalmente, parte-se de um suposto sujeito normal, enquanto uma referência ou um padrão. Qualquer “desvio" é considerado patológico - normalmente um déficit. Freud dá uma nova visão ao que é o normal: é preciso estudar as patologias para compreendermos o que seria a normalidade. Que se veja:

Achamo-nos familiarizados com a noção de que a patologia, na medida em que aumenta e torna mais grosseiro, pode chamar a atenção para condiçôes normais que de outra maneira não perceberíamos. Ali onde ela nos mostra um ruptura ou uma fenda pode haver normalmente uma articulação. Se lançarmos um cristal ao chão, ele se quebra, mas não arbitrariamente; ele se parte conforme suas linhas de separação, em fragmentos cuja delimitação, embora invisível, é predeterminada pela estrutura do cristal. Os doentes mentais são estruturas assim, fendidas e despedaçadas. (FREUD, 2010, p. 194-195).

Dito de outro modo: a descrição de uma patologia é, na verdade, um momento privilegiado para descrever o que está presente em todos os homens - basta que aconteça algo ("que faça o sujeito cair ao chão") para que as fendas apareçam... ${ }^{2}$

Se tomarmos a sério essa passagem, qualquer caso de histeria deveria valer para todos - ao conjunto "homem". Será verdade? Será que podemos tomar qualquer caso? Por conseguinte, Dora seria somente uma escolha arbitrária?

Aliás, a questão se aprofunda aqui, pois há um modelo para se pensar a histeria, mas não existe qualquer modelo para se pensar o que é o normal! Não há nenhum caso que poderia descrever o que possivelmente seria normal. Freud tende a mostrar que não podemos encontrar uma norma inerente à própria sexualidade, a qual pudesse nos permitir de uma vez por todas determinar o que

\footnotetext{
${ }^{2}$ Philippe Van Haute e Tomas Geyskens partilham dessa interpretação: "A abordagem clássica ao trabalho freudiano deixa de mostrar o que há nele de verdadeiramente original. A importância filosófica da psicanálise freudiana não reside no fato de que coloca o inconsciente em uma posição central ou de que observa a existência humana a partir da perspectiva da sexualidade. A originalidade de Freud não está nem mesmo em sua proposta de investigar a sexualidade primariamente em suas variaçôes patológicas. A verdadeira novidade do estudo psicanalítico freudiano sobre a sexualidade está no fato de que as várias patologias sexuais são pensadas como meros exageros de tendências compartilhadas por todos os seres humanos." (VAN HAUTE; GEYSKENS, 2016, p. 181).
} 
seria normal e o que não seria. Ele nos "força", assim, a repensar a existência humana à luz das diferentes patologias, porque estas só surgem quando a libido vê negada sua satisfação pelos "meios normais" (naturalizados pela cultura). Ou seja, para se entender a suposta normalidade, parte-se de casos singulares de patologia. Talvez não haja um exemplo de normalidade, porque esse seria um conjunto "fictício" que não recaia em caso algum. Se isso for verdade, sugiro a hipótese: o exemplo só recai num conjunto que possa ser verificado na realidade - náo há um exemplo de um conjunto real que se possa fazer a partir de uma ficção, porque se trataria de um exemplo sem qualquer conjunto verificável. Assim, um romance, por exemplo, não seria o exemplo de algo, mas apenas uma construção sem pretensão de verdade. Mesmo que, de algum modo, possamos reconhecer uma ficção como modelo para representar uma realidade qualquer, esse romance náo poderia ser um exemplo tal como no caso Dora um exemplo de um caso real que tenta dar conta de todo o conjunto histeria. Ou seja, um exemplo não pode ser uma construção fictícia.

Como disse, poucos pensadores se detiveram ou se deram o trabalho de investigar o problema do exemplo. Um deles é Giorgio Agamben. Em Homo sacer: o poder soberano e a vida nua I (1995), ele nos alerta para um paradoxo: "O exemplo, digamos, é excluído do caso normal não porque não faça parte dele, mas, pelo contrário, porque exibe seu pertencer a ele. Ele é verdadeiramente paradigma no sentido etimológico: aquilo que 'se mostra ao lado', e uma classe pode conter tudo, mas não o próprio paradigma." (AGAMBEN, 2007, p. 29).

Já em 1990, Agamben se detinha nesse paradoxo. Em A comunidade que vem, diz:

Um conceito que escapa à antinomia do universal e do particular nos é desde sempre familiar, é o exemplo. Qualquer que seja o contexto em que ele faz valer sua força, o exemplo se caracteriza no que ele vale para todos os casos do mesmo gênero e, ao mesmo tempo, é incluído entre eles. Ele constitui uma singularidade entre outros, que pode, entretanto, se substituir a cada um deles, ele vale por todos. Daí a pregnância do termo que em grego exprime o exemplo: para-deigma, o que se mostra ao lado (como o alemão Beispiel, o que joga ao lado). Pois o lugar próprio do exemplo é sempre ao lado de si mesmo, no espaço vazio em que se desenrola sua vida inqualificável e inesquecível. (AGAMBEN, 1990, p. 16-17). 
Seguindo essa concepção, Dora não seria um caso particular; nem também um caso universal. Dora seria singular. Por quê?

Agamben nos mostra que o exemplo tem uma espécie de "força". Um exemplo abarca outros casos e constitui, ao mesmo tempo, um conjunto. Ele é algo singular, porque não se encaixa nem na particularidade e nem na universalidade. Um caso particular é uma espécie de subconjunto do conjunto: particularmente, nesse caso $X$ de histeria, vê-se isso ou aquilo - algo que náo se estende ao todo. O exemplo não é universal, porque se trata de uma determinação pontual que tem a pretensão de valer em todos os casos do conjunto. Na histeria, o caso Dora tem que ser válido para todo e qualquer caso de histeria - "ele vale por todos". Ou seja, o exemplo tem que ter a força de uma singularidade. Contudo, o que é ser singular? Por exemplo: toda estória de vida não é, no fundo, uma singularidade? Se for assim, todos os casos poderiam servir de exemplo?

Se acompanharmos Agamben, a resposta é não. Ter uma estória singular, como são todas as estórias de vida, é algo contingente (no sentido aristotélico do termo: algo que pode ser ou pode não ser de tal modo, mas é necessário que seja ou não seja de tal modo). Ou seja, é necessário que haja uma estória qualquer, porém, isso não significa que essa estória possa valer como exemplo para qualquer outra estória. Ser singular? O que isso significa?

A singularidade não se confunde com a particularidade. Posso afirmar que um caso é particular: essa estória $X$, em especial, indica uma particularidade na histeria que não encontramos no caso Dora, por exemplo. É uma particularidade de caso de histeria. A histeria como conjunto é uma universalidade - um conjunto que contém todas as particularidades que são nomeadas histeria. Mas, dentre essas particularidades, extraímos um caso particular como singular. Isto é, um caso que, para além de sua particularidade, representa todas as particularidades. O singular, pois, é uma multiplicidade, como diria Gilles Deleuze, mesmo sendo apenas um caso. Ser singular é ser múltiplo em sua particularidade e representar o universal.

Bem, o que isso significa?

Agamben nos diz que o singular é algo que está dentro do conjunto, mas também fora - algo que serve como modelo, entretanto, não é necessariamente uma particularidade qualquer. Talvez toda questão esteja num outro ponto: um caso qualquer - qualquer um caso. O que é ser qualquer um? É esse 
o ponto de Agamben para pensar a comunidade que vem: nem particular, nem universal, mas qualquer um...

Podemos pensar o qualquer um em sua diferenciação com a exceção. A exceção, como propóe Agamben, não é um caso de exemplo ou modelo. E aqui parece haver uma contradição: para se explicar o que é uma exceção, usa-se um exemplo. Por quê?

A exceção não é um exemplo. Auschwitz não serve de exemplo para nenhuma situação. Auschwitz é um acontecimento [tal como se deteve em explicar Alain Badiou, em Ser e acontecimento (1988)] - um caso que abre a possibilidade de algo que ainda não era possível. Uma exceção funciona como um caso sem precedente e nem mesmo previsto. Dentro de um jogo de possibilidades, Auschwitz não se presta a nenhuma delas - trata-se de um caso que, na sua impossibilidade anterior, se torna uma abertura para um conjunto que ainda não sabemos exatamente qual é: há algo que aconteceu em Auschwitz da ordem do impossivel e que, mesmo assim, ocorreu. É como se Auschwitz nos tirasse o "conforto" de podermos pensar simplesmente a partir do possível: das possibilidades humanas. Auschwitz é uma exceção que nos obrigada a repensar o que é possível. Ou seja, a exceção instaura uma possibilidade que antes era impossível. Portanto, mesmo que se use um exemplo para se explicar o que é uma exceção, não se trata de um exemplo em si mesmo, mas de um acontecimento - um acontecimento que rompe com o que é possível e náo cabe em outro caso. Nesse sentido, uma exceção, por jamais ter sido prevista, não pertence a um conjunto $X$, porém, abre a possibilidade de um novo conjunto que se pode estabelecer.

O exemplo não é dessa ordem. Um exemplo é algo previsto - está dentro das particularidades possíveis num conjunto universal. Mas está contido no conjunto como singularidade - uma singularidade exemplar. O caso Dora seria essa singularidade. Daí a questão: por que uma singularidade serviria de modelo para se pensar?

A resposta de Agamben é a de que se trata "não de um ser que está em tal ou tal modo [essência ou existência], mas de um ser que é seu modo de ser e, desse fato, permanecendo completamente singular e não indiferente, é múltiplo e vale para todos" (AGAMBEN, 1990, p. 33-34). Exemplo é, nessas linhas, uma singularidade: um múltiplo. Ser singular é ser de tal maneira que esse ser se desdobra em si mesmo, sem referência a algo particular ou universal, e valendo, ao mesmo tempo, para todos. Um ser que tem por referência 
o seu próprio modo de ser e que, por isso, vale para o modo de ser em geral. Uma questáo ética por excelência: ser o que se é de forma própria - tal como Heidegger insiste em Ser e tempo (o Dasein é o ser no qual está em jogo o seu próprio ser e cabe a ele escolher ser próprio ou impróprio, sendo que ele está sempre sendo de uma forma ou de outra) - um ser que é engendrado pela sua própria maneira de ser.

O caso de exceção, reparemos, é exatamente o inverso: não se trata de uma escolha dentre possibilidades, mas algo que escapa de toda possibilidade. O exemplo é o caso - que se frise - que vale para todo o conjunto. Assim, o que há de tão singular na histeria de Dora que torna o caso singular, que vale para todos os casos?

Partamos desta afirmação: "Sócrates é um homem”. Essa afirmação é um exemplo?

Não. Com ela, tomamos algo particular, um homem em específico, que cabe dentro do conjunto homem. Quando digo que "Sócrates é filósofo", o mesmo se dá. No entanto, se dizemos que "Sócrates é $o$ filósofo", daí fazemos de Sócrates uma singularidade que vale para todos os outros filósofos. O que engendra Sócrates ser essa singularidade é seu próprio modo de ser e que se torna referência para todos os modos de ser filósofo. Ao mesmo tempo, Sócrates é simplesmente um caso dentre os casos do conjunto filósofo. Ele é um qualquer um entre os casos. Como qualquer um vale para qualquer um outro?

Agamben tenta explicar essa posição paradoxal:

Qualquer um é a figura da singularidade pura. A singularidade qualquer um não tem identidade, não é determinada pela relação a um conceito, mas ela não é mais simplesmente indeterminada; ela é antes determinada através de sua relação a uma ideia, quer dizer, à totalidade de suas possibilidades. (AGAMBEN, 1990, p. 68).

Nesse sentido, qualquer um é uma espécie de vazio de determinação - algo que não pode ser definível, mas que, simultaneamente, vale para todos os casos de um conjunto determinado. É singular, porque não pode ser exprimível, apenas exposto como exemplo. A conclusão de Agamben é que se trata de um acontecimento de um fora (AGAMBEN, 1990, p. 69). Essa ideia nos leva a retomar Michel Foucault, quando escreveu, em 1966, O pensamento do exterior. 
Foucault escreve esse texto tendo em vista a linguagem da literatura. Entretanto, sua reflexão cabe em nosso contexto. A linguagem da literatura não é da ordem da interiorização, diz Foucault. Ao contrário, ela se realiza e se desenvolve fora de si - ao desenrolar o seu próprio modo de ser, a linguagem literária se faz em uma dispersão da própria linguagem. Em outras palavras, ela se realiza no exterior da linguagem seu modo de ser (FOUCAULT, 2001, p. 548). Todavia, o que é exatamente essa experiência do fora?

Quando um discurso para de ser um pensamento que se interioriza e se volta ao ser mesmo da linguagem, ele se torna pensamento de fora (FOUCAULT, 2001, p. 553). Em outras palavras, quando a linguagem fala sobre o fora de toda linguagem, temos algo que Agamben denomina exemplo: ele é um fora, apesar de ser o dentro - como a linguagem do fora, ela é uma linguagem, mas que vale para a linguagem como um todo partindo de um fora da linguagem. A experiência do fora é esse deixar o ser o que se é - esse é exatamente o pensamento do exterior: o desenrolar daquilo que é próprio o faz ser exterior ao que lhe é próprio. Nesse caso, a particularidade de Dora é esse desenrolar de sua histeria, deixando-se ser tal como é ser histérico. Daí porque Agamben dirá que "o exemplo é o inverso simétrico da exceção: enquanto que esse é incluso pela sua exclusão, o exemplo é excluído pela sua apresentação de sua inclusão" (AGAMBEN, 2009, p. 26-27).

Tendo isso em vista, entendemos ainda mais uma diferença entre o exemplo e a exceção. A exceção, como Auschwitz, produz o que Agamben denomina vida nua. Quer dizer, tendo em vista que toda vida tem uma forma de ser, ocorre uma exceção quando, por algum motivo, a vida se torna sem qualquer forma de ser: torna-se uma vida nua. Esse ponto é central, porque esse acontecimento estranho faz do mulçumano - termo que se referia aos seres nos campos de concentração, os quais perdiam toda a forma de ser humano, tornando-se um ser fora do humano - ser um ser sem modo de ser. Não estamos aqui lidando com um exemplo. Um exemplo é algo próximo, algo que, por ser fiel ao seu modo de ser, representa todos e náo algo que perde sua forma de ser. Poderíamos afirmar que ele, o exemplo, não é assim, mas é seu assim (ele é seu modo de ser, uma singularidade que é assim, esse modo de ser assim, simplesmente um qualquer um).

Em outro momento de sua experiência intelectual, Agamben retorna ao problema do exemplo. Em seu livro Signatura rerum: sobre o método (2008), ele propóe pensar o exemplo a partir da noção de paradigma, pois esse é "um objeto singular, valendo para todos os outros da mesma classe, define a 
inteligibilidade do conjunto do qual ele faz parte e que, ao mesmo tempo, o constitui" (AGAMBEN, 2009, p. 18).

Agamben destaca como o exemplo não pode ser confundido com uma metáfora. Em uma metáfora, dizemos algo que representa um significado em outro caso que não se exprime senão em espécie de "transferência" de sentido, tentando dar visibilidade ao que se quer dizer. $\mathrm{O}$ exemplo não é transferencial: o caso Dora não é uma metáfora de outro caso de histeria, é um paradigma: um caso singular que não se isola do contexto e torna inteligível um novo conjunto que ele constitui como homogeneidade:

Tomar um exemplo é, portanto, um ato complexo, que supóe que o termo que faz funçáo de paradigma seja desativado de seu uso normal, náo para ser deslocado para outro domínio, mas, ao contrário, para mostrar o cânon desse uso, que não é possível apresentar de outra maneira. (AGAMBEN, 2009, p. 19).

Agamben amplia a concepção de exemplo, ao nos lembrar que, na obra de Foucault, o exemplo se dá segundo dois sentidos: exemplar e exemplum. Isso é, "não somente exemplar e modelo, que impõe a constituição de uma ciência normal, mas também e sobretudo exemplum, que permite reunir enunciados e práticas discursivas num novo conjunto inteligível e num novo contexto problemático" (AGAMBEN, 2009, p. 20). Essa concepção tem uma proximidade com a analogia - algo que não é nem particular, nem universal. Um exemplo pode ser análogo a outro. O exemplo, apesar de ser singular, não é único. Podemos ter vários exemplos que representam um conjunto, porém, não qualquer exemplo, somente aqueles que são análogos: vale para todos, inclusive para o análogo, sendo também um caso particular que, por representar todos, é singular. Esse é o estatuto paradigmático do exemplo, do qualquer um.

Ainda mais paradigmática é a escolha do exemplo - a identificação de um paradigma, pois não existe qualquer regra que se possa eleger para identificar o caso como qualquer um: "O paradigma implica um movimento que vai da singularidade à singularidade e que, sem sair desse, transforma todo caso singular em exemplo de uma regra geral que não é jamais possível de formular a priori." (AGAMBEN, 2009, p. 24).

Mas não se se está cego na escolha. Trata-se de um caso que foge do polo particularidade/universal - uma espécie de terceiro termo (singular, paradigmático): 
A aporia não se resolve senão se se compreender que o paradigma implica o abandono sem reserva do par particular-geral como modelo de inferência lógica. A regra (se ainda podemos falar aqui de regra) não é nem uma generalidade que preexiste aos casos singulares e se aplica aos dois, nem algo que resulta da enumeração exaustiva de casos particulares. Ou antes, o fato mesmo de mostrar o caso paradigmático constitui uma regra que, como tal, não pode ser nem aplicada, nem anunciada. (AGAMBEN, 2009, p. 23).

Que se perceba como essa concepção de exemplo foge da teoria das Formas de Platão e por isso cria um paradigma. Nenhum dos seres sensíveis que recaem no nome "homem", por exemplo, pode ser modelo para $o$ homem. Todos são cópias de um modelo - o que viria a ser singular, porque seria o que representa todos, sem ser qualquer um deles. O universal, entretanto, é uma ideia - e não algo que podemos apontar no mundo. Eis como Victor Goldschmidt assinala essa questão em Platão:

Postos diante de uma fotografia, exclamamos: "Este aqui é Pedro!" compreendemos que este cartão, com seus traços e suas sombras, figura Pedro, e sabemos muito bem que é impossível esse juízo sem saber, de antemão, quem é Pedro, e que esse juízo, dando o nome de um homem a um pedaço de cartão, não é de modo algum um juízo de identidade, ainda que atribua à cópia o nome de modelo. Do mesmo modo ainda, quando dizemos: "Pedro é grande", sabemos muito bem que mil outras pessoas também são grandes, e que nenhuma o é "pelo fato de ser aquilo que ela é"; nada pode, sem abuso, ser qualificado de grande, a não ser a Forma da Grandeza [universal], porque ser tal the é essencial. De modo que objeto algum ou pessoa alguma merecem qualquer qualificaçáo que seja, porque nada possui tal ou qual qualidade a não se de maneira temporária e contingente. (GOLDSCHMIDT, 1970, p. 41-42).

Daí porque a ideia, o universal, o que não pode ser representado senão em ideia, não pode ser um exemplo. O exemplo, por outro lado, deve estar fora do polo particular/universal.

Voltando ao caso Dora. Trata-se de um exemplo, porque suspende a referência de uso normal de um caso, tornando-se um caso singular qualquer, um modelo que não é anunciado na forma de "necessário", mas como necessariamente contingente - algo que não pode deixar de ser senão de modo contingente. De certa maneira, uma espécie de assinatura: tem a marca do que é válido, sem anunciar sua regra a priori. 
Por que, então, a escolha do caso Dora para pensar o que é escolher um exemplo?

O caso Dora é essa assinatura de "autoridade" do que seja histeria. A ousadia de Freud em escolher um caso em que diz ter "errado", por não ter percebido a questão da transferência, parece-me, é o que faz do caso singular. Ao descrever o caso, a transferência está a todo o momento em jogo, mas não descrita - é porque a regra ainda não tinha sido anunciada (o fato de ser necessário que o caso de histeria apresente a transferência como modelo de neurose de transferência - tal como era classificada a nosografia, na época). Mesmo só sendo anunciada a regra do caso anos depois, num posfácio, estava lá a singularidade do caso: ele unifica o múltiplo, contudo, que não está contido em nenhum dos casos - é o modelo ideal e real (não fictício) que serve de paradigma para o conjunto histeria.

Finalmente: por que eu mesmo usei Freud como exemplo para pensar o que é exemplo? De tudo o que foi dito, a escolha teve um critério simples: Freud é um caso singular.

MANZI, R. How to choose an example? - from anyone to any one. Trans/form/ação, Marília, v. 42, n. 4, p. 187-200, Out./Dez., 2019.

ABSTRACT: How to choose an example? What happens in dealing with simple data could in fact be the most complex of things: the criterion of choice. Some cases are examples and others are not. Why? The purpose of this text is to try to give some criteria for this sort of choice. The path chosen for this was to take a case of Freudian psychopathology: the case of Dora. Why is this case considered an example of hysteria? To answer this question, we recurr to Agamben's ideas, especially his distinction between example and exception. Foucault's "thought from outside" is also discussed, along with the ideas of other thinkers. The text seeks to determine why an example lies in a case of singularity something that is neither particular nor universal. There is a paradigm in providing an example: not all are worthwhile. Why?

KEYwORDs: Example. Particularity. Universal. Singular. Model. 


\section{REFERÊNCIAS}

AGAMBEN, G. La communauté qui vient: théorie de la singularité quelconque. Tradução de Marilène Raiola. Paris: Éditions du Seuil, 1990.

AGAMBEN, G. Homo sacer: o poder soberano e a vida nua I. Tradução de Henrique Burigo. Belo Horizonte: UFMG, 2007.

AGAMBEN, G. Signatura rerum: sur la méthode. Tradução de Joël Gayraud. Paris: Vrin, 2009.

DELEUZE, G. Différence et répétition. Paris: PUF, 1993.

FOUCAULT, M. La pensée du dehors. In: EWALD, F; DEFERT, D. (ed.). Dits et écrits I, 1954-1975. Paris: Quarto Gallimard, 2001.

FREUD, S. A dissecção da personalidade psíquica. In: Obras completas - volume 18. Tradução de Paulo César de Souza. São Paulo: Companhia das Letras, 2010.

FREUD, S. Análise fragmentária de uma histeria: “o caso Dora”, 1905 [1901]. In: Obras completas - volume 6. Tradução de Paulo César de Souza. São Paulo: Companhia das Letras, 2016.

GOLDSCHMIDT, V. A religiāo de Platão. Tradução de Ieda e Oswaldo Porchat Pereira. São Paulo: Difusão Europeia do Livro, 1970.

HEIDEGGER, M. Ser e tempo. Tradução de Fausto Castilho. Ed. bilíngue. Campinas: Editora da Unicamp, 2012.

LACAN, J. De la psychose paranö̈aque dans ses rapports avec la personnalité: suivi de premiers écrits sur la paranoïa. Paris: Seuil, 1975.

VAN HAUTE, P.; GEYSKENS, T. Psicanálise sem Édipo? Uma antropologia clínica da histeria em Freud e Lacan. Tradução de Mariana Pimentel. Belo Horizonte: Autêntica, 2016.

Recebido: 04/04/2017

Aceito: $07 / 11 / 2017$ 
MANZI, R. 